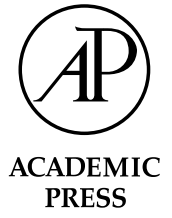

Cladistics 19 (2003) 356-368

www.elsevier.com/locate/yclad

\title{
The repugnant and the mature in phylogenetic inference: atemporal similarity and historical identity
}

\author{
Arnold G. Kluge* \\ Museum of Zoology, University of Michigan, Ann Arbor, MI 48109, USA
}

Accepted 4 June 2003

\begin{abstract}
The significance of "being similar" in the inference of species relationships is refuted once again (see also Hennig, 1966, Phylogenetic Systematics, Univ. of Illinois Press, Urbana, IL). Without merit is Rieppel and Kearney's (Biol. J. Linn. Soc., 2002, $75,59-82$ ) claim that submitting the relational property of topological similarity, their preferred definition of character, to falsifying tests of similarity benefits that kind of inference. Such a priori uses of similarity, in character analysis, are consistent with observational theory, where a character is defined intensionally in terms of immutable properties. However, the induced hypotheses that follow from this theory, not the deductive test that Rieppel and Kearney wanted, remain controversial, because their predictability is a consequence of circular reasoning, and their projectabality fails empirically from incongruent observation reports. Further, a category mistake is made when the abstract, similarity-defined, group of organisms is reified, as a part of history. In addition, Rieppel and Kearney failed to provide a special theory for similarity, which renders similarity scientifically repugnant (Quine, 1969, Ontological Relativity and Other Essays, Columbia Univ. Press, New York). A return to Hennig's (1966) evolutionary concept of evidence, as transformation series, is urged, and from which a testable character hypothesis can be formulated. There is no one operation for determining character states in this system - it can be anything that leads to the testable hypothesis of synapomorphy, as an historical identity relation. Character compatibility and conjunction, but not similarity, provide a priori tests in phylogenetic character analysis. In turn, the phylogenetic system of inference leads to explanations of homology, as historical identities, which exemplifies the goal of achieving a mature state of historical knowledge (not of Quine, 1969). Such maturity obtains from attempts to falsify hypotheses of species relationships with severely tested evidence, not from induction of "the" observation statement that Rieppel and Kearney sought to justify their true belief in a hypothesis of relationships.
\end{abstract}

(C) 2003 The Willi Hennig Society. Published by Elsevier Inc. All rights reserved.

If observation and description constitute science then landscape artists must be scientists.

Like Charles Darwin, Willi Hennig attacked the typological thinking of his time and especially that of the German idealistic morphologists/phylogeneticists. In denying evidence of the baupläne, i.e., "typical similarity” (e.g., Naef, 1917, p. 16; 1919), Hennig's (1966, p. 9) evolutionary definitions of character and homology were free of idealism and typology, including the explanatory concept of material essentialism (see also

\footnotetext{
${ }^{*}$ Fax: +734-763-4080.

E-mail address: akluge@umich.edu.
}

Mindell and Meyer (2001), but who did not cite Hennig). ${ }^{1}$ Indeed, the preeminence of Hennigianism over phenetic and neo-Darwinian systematic approaches has been traced to Hennig's attacks on the significance of being similar (e.g., see Farris, 1977). Why is it then that references to similarity are again becoming commonplace in the systematics literature? Is it merely sloppy language or is it a consequence of some improved

\footnotetext{
${ }^{1}$ According to Hull (1964, p. 317), the three essentialistic tenets of typology are (1) the ontological assertion that forms exist, (2) the methodological assertion that the task of a science is to discern the essences of those things, and (3) the logical assertion concerning definition (i.e., Aristotle's restatement of the inherent essence or nature of a thing). Material (methodological) essentialism is distinct from a purely metaphysical interpretation.
} 
insight provided by that kind of science? With regard to the former possibility, Quine $(2000$, p. 289, my italics; see also Goodman, 1970) offered "In daily discourse we all do indeed persistently declare things to be similar in various degrees, and a definition of that relation is notoriously lacking." And to which Quine added that "It is an unconscious projection of perceptual similarity."

Earlier, Quine (1969) had made the point that perceived similarity can be well understood only in the context of special circumstances, where the concept of similarity is tied to the notion of natural necessity or lawfulness peculiar to the science at hand; minimally, a theory is required (Goodman, 1970, p. 22). For example, the necessity on which the Periodic Table is now founded is atomic number (the number of positively charged protons in their nucleus), and it is only after a given science's special theory has been hypothesized, which is the case with atomic theory in the above example, that similarity can be tested in light of that necessity. Perhaps it is the increasing emphasis on the supposed critical nature of the "test" that accounts for the mounting references to similarity in phylogenetic inference. Indeed, several authors explored the significance of the test of similarity, including Bock (1977, p. 882), Platnick (1978, p. 366), Patterson (1982a, 1988), and Lipscomb (1992). Most recently, Rieppel and Kearney (2002, hereafter RK) argued at considerable length for formulating and testing character hypotheses in terms of similarity.

RK's lengthy contribution will be used as the basis for revisiting character similarity and testability, followed by an evolutionary hypothetico-deductive definition of character and homology, where I ascribe no special significance to similarity, neither conceptually nor operationally. My understanding of the issues relating to similarity has benefited from distinguishing between "repugnant" and "mature" (Quine, 1969). ${ }^{2}$ As I will further explain below, scientists must have an aversion to similarity in the absence of a special accompanying theory. Also, according to Quine (1969), once a disposition term is legitimized by defining the relevant similarity standard, with regard to some special theory, the disposition is apt to become known, thereby bypassing the need to refer to similarity. Thus, mature sciences are not expected to retain their highly specific similarity notions, because those notions are not theoretically important. RK's research program concerning similarity will also be evaluated against a theory of scientific progress of this kind.

The distinction between abstract and concrete is also important to my position on similarity and testability, for which the following clarifications are offered (see

\footnotetext{
${ }^{2}$ Quine's use of the term "repugnant" is repeated herein, not because it is gratuitous or condescending, but because it underscores the failure of observational theory in science, where pure observation reports are used to erect an inductivist epistemology.
}

also Frost and Kluge, 1994). Various references will be made to abstractions in the text to follow. While "class" will refer to conceptualizations of all "kinds," "natural kind" is restricted to the kind of class that exhibits nomological, lawful, necessity. A natural kind is defined with regard to properties that are both necessary and sufficient for membership, and its essence involves a generalization that is not accidental and explanatory. Natural kinds are then universals, matters of intensional definition, which are spatio-temporally unrestricted. The concept of essentialism applies to the universal "Forms" of Aristotle, but not to the spatio-temporally restricted thing (Hull, 1964, 1978). Curiously, Mahner and Bunge (1997, p. 221) accepted the nomological necessity of natural kinds, but concluded that "naturalness comes in degrees"! With regard to the concrete, these are the spatio-temporally restricted, i.e., empirical things or objects. Things, such as organisms and species, are selfdefining, and reference to them is made with regard to extension. For further details concerning intension and extension see Kluge (2004, Table 1.1; see also Frost and Kluge, 1994).

\section{Atemporal similarity ${ }^{3}$}

RK emphasized the significance of falsification in phylogenetic inference (for this recurrent theme see also Rieppel, 1980b, p. 317; 1988, p. 42, 47, 59, Fig. 4). In particular, they attempted to demonstrate how the data used to test species relationships might be rendered more severely tested by employing a similarity definition of character that is empirically falsifiable. Effectively, their claim was that phylogenetic hypotheses will be more convincingly tested the more effort put toward a priori character analysis involving tests of similarity. The empirically testable nature of the "critical" discussion to which they frequently appealed is undeniable (pp. 61-62; italics in the original). As they stated: "A meaningful character is thus based upon a character description that can in itself be critically evaluated, tested and potentially rejected. ... The critical discussion entails 'attempted refutations, including empirical tests' (Popper [1972, p. 80])." Clearly, RK enjoined a falsifying test of similarity in their recognition of a character (see also below).

The significance of falsifiability is certainly not a new idea in science (Popper, 1959; see also Farris et al., 2001; Kluge, 2001, 2002, 2003; see, however, Patterson, 1978,

\footnotetext{
${ }^{3}$ The contrasting terms acausal/causal, ahistorical/historical, and atemporal/temporal employed herein follow previous usage (e.g., Rieppel and Grande, 1994, pp. 229-230; Brady, 1994). Acausal/ ahistorical/atemporal and causal/historical/temporal refer not to the nature of the character but to the kind of inference in which the character is used, such as pattern cladistics and phylogenetic systematics, respectively.
} 
1982c) nor is the point of view that similarity may be an operational part of character analysis (e.g., Wiley, 1975, p. 235; Bock, 1977, p. 882; Platnick, 1978, p. 366; 1982, p. 283; Cracraft, 1979, p. 33; Rieppel, 1980b, p. 315; Patterson, 1982a, pp. 46, 47, 1988; Lipscomb, 1992; Brower, 2000a,b; Whiting et al., 2003). What is novel in RK's thesis is their claim that a character is both definable and falsifiable with regard to similarity (pp. 61-63, 66, and elsewhere).

Consider RK's definition of character (p. 61): "a logical relation established between intrinsic attributes of two or more organisms that is rooted in observation." "This is what I will call an operational/phenetic definition of character, where the datum, $d_{\mathrm{p}}$, is an observed property of an organism, a property instantiated by an organism (pace Woodger, 1952). This definition is an ordinary categorical proposition, which follows from facts-simple atomic propositions, such as "Olivier likes wine." As for an example of a more complex proposition, one familiar to comparative biologists, "organism A has part X with property 1," or more specifically, "this snake has a caudal vertebra with a hemapophysis," or "this snake's ND2 gene sequence has an adenine at nucleotide position 297." So defined, a character involves a basic statement (proposition), which is sensed and becomes the content of a declarative sentence employed in its typical form. As an aside, these examples illustrate a basis for distinguishing a character (part X) from its states (property) (contra Bock, 1973, p. 387; Patterson, 1982a, p. 25; Platnick, 1979).

The theory of propositions concerns only the nature of the subject and the predicate, which in the case of a phylogenetic character refer to the organism and the particular property and which are logically connected by referring to some part of the organism. A predicate is, by extension, the class of objects that it describes. For example, the extension of hemapophysis is the class of hemapophysis things. On the other hand, the properties of an object are intensional. Intension is the action that picks out precisely definable circumstance(s), the condition(s) in the present circumstance that must be satisfied to be described by the predicate. For example, the intension of hemapophysis might involve any number of assessments, as per intrinsic properties (e.g., mass, composition, development), relational properties (e.g., topological), primary properties (does not require a sentient power), secondary properties (phenomenal; requires a sentient power), qualitative properties, quantitative properties, etc. (there is no generally agreed upon list or classification of properties).

\footnotetext{
${ }^{4}$ This definition is incomplete without reference to some property to which similarity can be referred. RK made such references elsewhere in their paper, such as repeatedly stating their preference for the relational property of topological similarity (p. 64).
}

A claim that one observes two or more organisms with similar properties is to maintain that those organisms are members of the same intensionally defined class, $D_{\mathrm{p}}$. Mahner and Bunge (1997, pp. 219-220) used not only the "scopes of properties" to delimit such classes but also the concomitance of different properties as the basis for claiming the lawfulness of those that are natural kinds (see, however, Sober, 1981). Projectability, a property of predicates, is the degree to which past instances can be taken as guides to future ones. For example, that all those individuals of the class dog that have been observed thus far are four-legged is considered a plausible basis for predicting that all dogs observed in the future will have four legs. Thus, fourleggedness is a projectable predicate. Whether it is "kinds" or "natural kinds," an intension of similarity is involved in the classification.

Each usage of a proposition is true or false, which is not known in any particular instance. "Testing" $d_{\mathrm{p}}$ usually begins with what the predicate is, with regard to its relational and/or intrinsic (e.g., topological and developmental) properties, followed by what that predicate's relation is among organisms, $D_{\mathrm{p}}$. In the sense of the theory of propositions, character analysis is concerned with both individual and generic properties what makes an organism an organism and what makes an organism a member of a class of equivalent organisms of some kind, respectively. It is on the basis of this brief review of observational theory (see also Kluge, 2004) that the details of RK's thesis, that similarity constitutes the basis for character formulation and its falsifiability, will be evaluated.

RK argued the need for testing observation statements, because those propositions are the only basis for determining object-level reality, what a character is, and what the relation of a character is among organisms. According to these authors then, only by having attempted to falsify $d_{\mathrm{p}}$ and $D_{\mathrm{p}}$ can the results of phylogenetic analysis be justified, such as provided by a character congruence analysis. What RK suggested, as character analysis, is an exercise in the Popperian logic of scientific discovery (Popper, 1972, p. 80; Kluge, 2002), and there can be no recourse to the "interpretation functions" and "truth values" (truth table) of the theory of propositions. The falsifying tests of $d_{\mathrm{p}}$ and $D_{\mathrm{p}}$ must come from the observation hypotheses themselves, i.e., the properties and the relation of those properties among organisms.

RK's definition of character is not unique in systematics or phylogenetic inference more specifically. For example, as Lipscomb (1998, p. 53, boldface in the original; see also Grande and Rieppel, 1994, p. 261; Rieppel, 2002, p. 195) stated, "[t]he observable parts, or attributes, of organisms which can be examined for similarity or difference are called characters." Likewise, Kitching et al. (1998, p. 201) held a 
character to be "an observable feature of an organism used to distinguish it from another." Even the pheneticists' definition is much the same, that a character is operationally homologous if the states are "very much alike in general and in particular" (Sokal and Sneath, 1963, p. 70).

RK argued that character hypotheses (what they called primary conjectures of homology; see de Pinna, 1991) should be based on the classical observational techniques of comparative morphology, emphasizing the relational property of topological similarity (see also Russell, 1916, p. 246; Jardine, 1969 , p. 328$),{ }^{5}$ and less often according to the "subsidiary" techniques of assessing special similarity and intermediate form (see also Hennig, 1966, p. 94), because those three techniques provide a priori tests, with the unfalsified shared similarities becoming more severely tested evidence. Paraphrasing (p. 72), RK's favored test of similarity of primary homology involved the establishment of one-to-one relationships of structures observed on organisms, and a falsifying test was "the lack of topological correspondence" (p. 70). Summarizing their position (p. 72), they stated that "[t]he type of testing described above for conjecturing [primary] homology is rigorous and requires in-depth and timeconsuming study of structural complexity, which is at odds with recent trends that diminish the role of careful character analysis in morphological systematics." In the present context, complexity is understood (usually) with regard to the relational properties of an organism's anatomical parts, the more such relations can be specified the greater is the recognized degree of complexity.

The authors' intention to provide more severely tested evidence in phylogenetic inference, not casually identified relational properties or systematically biased basic statements, is considered laudable (e.g., see Rieppel et al., 2002). However, significant problems exist in what they, and many others, have emphasized as significant in the definition of character and its tests, namely similarity. Also, there is the more general philosophical issue of whether their research program is really concerned with "knowing" in the objective knowledge sense of Popper or whether it is just another exercise in justifying true belief in a hypothesis of relationships, with regard to knowing the "truth value" of characters.

\footnotetext{
${ }^{5}$ The term "connectivity" is often associated with the concept of topology, but not always with the same meaning. As RK (p. 66; see also Rieppel, 1980a, p. 85 ; 1989, p. 54) stated, "[a]s ontogeny adds a dynamic component to topology, the latter becomes connectivity," whereas according to Rieppel (1990, p. 302; 1994, pp. 71-72), the connectivity of topology originated with Geoffroy Saint-Hilaire's explanation "principe des connexions"- compensated change in structures due to the constancy of blood volume.
}

\section{Normative problems}

RK were not always clear that similarity resides in the properties of organisms. Even their character definition lacks that necessary reference (p. 61). ${ }^{3}$ This deficiency is also true of many other character definitions (e.g., Grande and Rieppel, 1994; Kitching et al., 1998; Lipscomb, 1998; Rieppel, 2002). The problem is this: things do not contain similarity. It is the particular properties in a similarity relation that gives meaning to the comparison. As Ghiselin (1966, pp. 212-213) succinctly put it: "It is one thing to say ' $x$ is similar to $y$ in possessing property $a$.' It is another to say that ' $x$ is more similar to $y$ than to $z$,' or that ' $x$ is twice as similar as $y$.' Without reference to intrinsic properties, these latter two statements are pure nonsense." In other words, the proposition must be complete, as in "organism A has part X with property $1 . "$

Likewise, RK's basic thesis with regard to the testability of observation proposition is flawed fundamentally, because those statements are not falsifiable, neither $d_{\mathrm{p}}$ nor $D_{\mathrm{p}}$. It is the inductive power of similarity-prediction and projectability - that is emphasized in tests of observation hypotheses (e.g., Goodman, 1965, 1970, p. 23; see, however Sober, 1981, p. 159), not their Popperian falsification, to which RK repeatedly referred. The testability of a Popperian hypothesis has to do with its improbability, not the likelihood of it being verified (Kluge, 2001; contra de Queiroz and Poe, 2003).

However, even if RK had settled for a test of induction (see p. 66), those kinds of observation hypotheses come with the well-known criticism of circularity - the idea of similarity is understood with regard to shared properties, and the idea of predictive power is understood with regard to the capacity to facilitate inference of additional properties. Furthermore, similarity and predictive power do not necessarily distinguish a real property from a pseudoproperty (Goodman, 1965). As Sober and Lewontin (1982, pp. 176-177) pointed out, "a predicate can pick out a real (causally efficacious) property in one context and fail to do so in another," and "the point is that a certain natural interpretation of a biological phenomenon helps to indicate how we ought to understand a rather abstract metaphysical issue," such as this. Returning to Quine (1969; see also Goodman, 1970; Sober, 1981), what is necessary for a realistic interpretation of similarity is a special theory that can explain similarities. Also, as will be discussed further, projectability fails, because it does not cover the observed patterns of similarity that are inconsistent. For example, the projectable predicate of four-leggedness of the class dogs does not predict a three-legged dog.

Unfortunately, RK did not specify a special theoretical meaning in their definition of character, and therefore it is difficult, if not impossible, to evaluate the application of any kind of definition of character and 
test that they might have proposed. Such a significant lapse is curious, because RK did point out (p. 62; see also Rieppel, 1989, pp. 54, 56; 1991, p. 93; 1994, pp. 69-70) that "theory ... always precedes observation." Nonetheless, the relation that RK had in mind was something that they argued is to be discovered by empirical test, and therefore a theoretical basis for the observation of similarity must be specified a priori, as part of the explanans of whatever scheme of inference is involved. Without an underlying theory of similarity, their thesis of testing it can have no real merit (Nagel, 1979, pp. 79-105; Beatty, 1982, p. 31; Grant, 2002, p. 96; see also Brady, 1983, pp. 57-58).

Clearly, a temporal/historical, transformational relation among character states (e.g., Hennig, 1966; Platnick, 1979, 1982) - an evolutionary interpretation of character-was not part of RK's definition of character (see also Rieppel, 2002; Patterson, 1982b,c). ${ }^{6}$ To be sure, as they emphasized (pp. 77-79), their definition of character is purified of that assumption (see also Rieppel, 1980a, 1991, p. 94, 98; 1992, 2002; Patterson, 1982a,b,c, 1988, p. 304; Brady, 1983, p. 59; Lipscomb, 1992; Brower, 2000a,b), since it is only after the observed similarities among organisms have been corroborated with character congruence that an atemporal relation may be "hypothetically explained as an historical relation." This is the familiar pattern cladistic thesis (e.g., Rieppel, 1991, p. 98; 1992, p. 713; see also Brady, 1983; Patterson, 1982a,b, p. 306; 1983, 1988; Brady, 1985, p. 119; Brower, 2000a,b, 2002). ${ }^{7}$ Reiterating RK's position, the theory and practice of establishing an atemporal (acausal) relation in evidence precedes that of establishing temporal (causal) historical relationships among species, where the former is based on intensionally defining a character and testing it in terms of similarity. The crux of this normative problem, as Quine (2000) explained, is that there is no general theory of causal determination for similarity/similarities, ${ }^{8}$ contrary to what one might think, given the terms' frequent use in ordinary, technical, and even scientific discourse.

Finally, RK (pp. 59-60, 64, 70) repeatedly mentioned that recognizing a character, $d_{\mathrm{p}}$, involved the problem of "abstraction." Their concern is well founded, of course, but the abstraction for which they expressed concern comes from having intensionally defined characters on

\footnotetext{
${ }^{6}$ Some pattern cladists (e.g., Brower, 2002, p. 223) have denied making the assumption of "descent with modification," only to follow with the claim that "the [pattern] cladistic method is based upon the minimization of ad hoc hypotheses of observed character state transformation ..." What "transformation" means in the context of species relationships, if not evolution, remains a mystery (e.g., see also Brower, 2000b, p. 13, 15).

${ }^{7}$ An especially clear and concise description of pattern or transformed cladism can be found in a little-cited paper by Patterson (1982b, pp. 304-306).

${ }^{8}$ This does not deny perceptual theory.
}

the basis of the similarity of properties, i.e., their determination of an abstract (class) concept. As I will emphasize below, abstraction does not accompany all approaches to character delimitation, such as those concerned with historical things.

\section{Descriptive problems}

The descriptive issues relating to RK's position concern the nature of similarity and the definition of the kind of quality space (the parameters of the similarity space), the totality of the space, and the identification of the paradigm object (what is being compared for their similarities $-x$ and $y$ are more similar to each other than either is to $z$, etc.). As already noted above, to make a similarity comparison is problematic, because similarity is "merely the subjective impression of resemblance... similarities are real, similarity is subjective" (Ghiselin, 1966, p. 213). Moreover, even quantified similarity may be judged subjective, because it is without extensive orderings, which is to say that similarity, as such, does not obey the associative or commutative laws of mathematics. Repeatability, including that which is judged from the consensus of opinion that is expected from intersubjectivity (Rieppel, 2002), does not necessarily overcome the subjective nature of what is claimed in a similarity relation. For example, while there may be subjective agreement as to redness, not all instances of red are precisely the same.

Also, as noted above, RK argued the significance of three similarity space qualities - the relational property of topological similarity, special similarity, and intermediate form. Here a problem obtains whether those qualities are used separately or whether some overall quality of the similarity space is specified, as for example Carine and Scotland (1999) employed in their modified version of three-taxon analysis (Kluge and Farris, 1999). To begin with, the basis for topology being considered the most important property on which to evaluate similarity, as argued by RK (see review by Rieppel, 1980b, p. 315), has yet to be justified with regard to it actually having a lower error rate in the identification of homologues, not withstanding Brady's (1994) attempt to define "transformation" in static terms, with the principle of "topological invariance" as its cause. But, in any case, as Russell (1916; see also Riedl, 1975; Rieppel, 1988 , pp. 45, 52) pointed out, the relational property of topology presupposes the same measure of similaritythat of similarity of position-and that leads to a methodological regress, arguably an infinite one. Thus, any particular relational property of topology is in principle founded on a notion of overall (topological) similarity.

To involve the qualities of special similarity and intermediate form in induction, including that of 
connectivity (the ontogenesis kind, not that of topological invariance, sensu Geoffroy Saint-Hilaire, 1818, p. xxvi), ${ }^{5}$ some measure of topological correspondence among organisms must have already been established. That being the case, I fail to see how RK can have argued that, with the failure of the test of character hypotheses according to the relational property of topological similarity, the "other" techniques can be used as tests. Logically at least, what they claimed as "beyond topology" cannot be divorced from suppositions of the relational property of topological similarity (pp. 75-77). My point is that the tests of connectivity (ontogenesis), special similarity, and intermediate form that RK advocated are not independent of their test of the relational property of topological similarity. If there is to be real meaning to discovery in a priori character analysis then all tests must be independent, and the more the better (Kluge, 1989, 2003). Arguably, RK can claim only one "test," one of overall (topological) similarity. That the "frame of reference" for the relational property of topological similarity (Rieppel, 1988) may be defined by connectivity (ontogenesis), special similarity, and intermediate form does not mean that there are additional, independent, tests of similarity involved. While some may be satisfied with metaphor and simile in perceptual theory (see, however, Goodman, 1970, p. 22), the scientific recognition of what a character is requires testing, and the independence of those tests is critical.

If the similarity space were to be defined in more than one dimension, as discussed above and as might be summarized by a multivariate statistic such as principal components, then it would be an $n$-dimensional kind of similarity. However, with regard to the totality of such a similarity space, the problems of holism are confronted, as is the arbitrariness of selecting just some part of that space to observe and describe. A fundamental question that RK did not address is how much similarity is enough when a relational property of topological similarity is stated? As Popper (1957, p. 77) discussed,

\footnotetext{
If we wish to study a thing, we are bound to select certain aspects of it. It is not possible for us to observe or to describe a whole piece of the world, or a whole piece of nature; in fact, not even the smallest whole piece may be so described, since all description is necessarily selective.... [For example,] a piece of the world, such as a sparrow nervously fluttering about, may be described by the following widely different propositions, each corresponding to a different aspect of it: 'This bird is flying!-'There goes a sparrow!'-'Look, here is an animal!''Something is moving here.'-'Energy is being transformed here.'-'This is not a case of perpetual motion.'-'The poor thing is frightened!' It is clear that it can never be the task of science to attempt the completion of such a list, which is necessarily infinite.
}

Where one stops in assessing the relational property of topological similarity is arbitrary.

Also, as RK admitted, whatever a priori test(s) of similarity is applied, the unfalsified results can still be inconsistent in the final analysis of character congruence (e.g., Rieppel, 1980b, pp. 316-318; 1989, pp. 54-55; 1994, p. 94). RK focused on morphological similarity, and one might argue that the lack of effectiveness of the a priori test(s) is simply due to systematic error-for example; that uncertainty due to an investigator's limited ability to observe. To be sure, no one should be surprised that the character "wing" is incongruent when considered with regard to the phylogenetic relationships of a group such as tetrapods, which is not to say that some kinds of wings, e.g., the bird "wing" and the bat "wing," cannot be diagnostic of their respective subgroups. However, regardless of a priori test(s) and the elimination of systematic error, similarity has been proven empirically not to be enough in phylogenetic inference (contra Sober, 1988, pp. 130-131). In molecular phylogenetics, where each nucleotide state, A, G, C, and $\mathrm{T}$, is defined intensionally in terms of its physicochemical properties, those states nonetheless evolve independently. In other words, when comparing a nucleotide position in different organisms, not all A's are necessarily the same historically, not all G's are the same historically, etc. Complicating this matter, however, as Källersjö et al. (1999) found, those independently evolved molecular states can still be phylogenetically informative at less inclusive levels of taxonomic comparison. To claim that one observes two or more organisms with similar (even identical) properties, and therefore that those organisms must be members of the same abstract (class) concept, is not sufficient to infer some common cause, either baupläne or common ancestry. Likewise, there is an apparent failure of the projectability of a natural kind, such as Tetrapoda, when caecilians are excluded owing to the systematists' failure to observe their tetrapodness. As Hennig (1966) underscored, phylogeneticists should not be in the business of presupposing the significance of any particular similarity, with regard to its "kindness" and the abstract group that it intensionally defines.

Finally, it is the relationships among taxa that are of ultimate concern, with the terminal taxon being species in all phylogenetic analyses (Hennig, 1966, p. 71; Kluge, 2004). Unfortunately, RK did not address in any detail their use of similarity in relation to species, and we are left to infer the nature of that taxon. Species have been considered natural kinds, eternal and immutable, or things - parts of history, with a definite beginning and end and the property of being changeable during that time. RK's emphasis on similarity, and what a predicate's relation is among organisms, $D_{\mathrm{p}}$, indicates that their preference is for species as natural kinds (see the next section). Clearly, it is not enough to say that we group only characters, and not organisms, into taxa, because properties are not separate from the things that possess them. Moreover, without reference to species, the sexes, and the different stages in the life cycle being 
compared (e.g., semaphoronts) can be referred to different similarity classes of organisms. Rieppel's (1992, p. 706; my italics) claim that it is simply impossible to specify homology "in light of present biology of speciation processes" is beside the point, because the relations of the sexes and life history stages are established on criteria other than homology.

Like RK, Lipscomb (1992, p. 52; see also Maslin, 1952; Bock, 1977, 1989) argued at length for a criterion of repugnant similarity in the inference of species relationships, where the adjacency of the states of a multistate character is hypothesized on the basis of similarity, without reference to evolution (see, however, Pogue and Mickevich, 1990; Hauser and Presch, 1991). As Lipscomb (pp. 51-52) put it, the "degree of homology among states" is to be determined by "a similarity criterion," which defines a "hypothesized [character] transformation series." "[A]n order of the states is postulated so that states that are most similar are adjacent to each other." "It is not necessary to make evolutionary assumptions about character state changes to assess the relative similarity of the states ..." Aside from pondering the meaning of ancestordescendant states being homologous to some "degree" (see also Brower, 2000b, 2002), Lipscomb's version of multistate character analysis can be rejected, like that of RK's a priori analysis of homology relations, because the property of similarity is without a priori epistemological accessibility (see also Patterson, 1988), in addition to being circular and without predictibility. As Hennig (e.g., 1966, p. 89; see also Platnick, 1982, p. 282) pointed out, there is no necessary relation between similarity and the evolutionary concept of character transformation.

\section{Extrapolations}

As already noted, RK's definition of character (see also Grande and Rieppel, 1994; Kitching et al., 1998; Lipscomb, 1992, 1998; and especially Rieppel, 2002) involves the intensionally defined, the abstract, $d_{\mathrm{p}}$ and $D_{\mathrm{p}}$, and without reference to some theory of transformation in that definition, class membership is a function of the a and not-a conditional of set theory (Rieppel, 1980a, pp. 84-85; 1989, p. 53; Patterson, 1982a,b, 1988; Brady, 1983). For example, with regard to $D_{\mathrm{p}}, \mathrm{A}$ and $\mathrm{B}$ organisms are members of set $\mathbf{a}$, with regard to some kind of similarity space quality, such as the relational property of topology. Set theory is then an atemporal relation of the paradigm objects. In the present context that would be something like an Aristotelian downward classification by logical subdivision, based on observations made on organisms (Rieppel, 1989, p. 56). For example, an (A,B,C,D) set of organisms may be classified $(((\mathrm{A}, \mathrm{B}) \mathrm{C}) \mathrm{D})$, where the set $(\mathrm{A}, \mathrm{B})$ is defined intensionally with regard to some $a$ quality of similarity, the set $(\mathrm{A}, \mathrm{B}, \mathrm{C})$ is defined intensionally with regard to some other a quality of similarity, and the set (A,B,C,D) is defined with regard to yet some other $a$ quality of similarity, with the sets being perfectly inclusive, $(((\mathrm{A}, \mathrm{B}) \mathrm{C}) \mathrm{D})$. This is classification in the true sense of that word, where group membership is determined precisely in the nonhistorical terms of intensional definition, properties necessary and sufficient for inclusion in a set (e.g., see Brady, 1983). Venn diagrams and probability arguments have often served to illustrate the inclusive/exclusive form of such sets in the inference of species relationships (e.g., Patterson, 1982a, Figs. 1-5, 7; 1982b, Fig. 4; 1982c, p. 285). ${ }^{9}$

Aside from excluding the special theory of evolution as background knowledge for their intensionally defined class concept $D_{\mathrm{p}}$, RK gave no hint with regard to what theory they would entertain as a major premise. However, other than the mere expectation "that organic homologies can be ordered hierarchically" (Brady, 1983, p. 51), one non-evolutionary theme has been cited over the years, even in the recent literature - "the necessary concept in homology is essential structural similarity" (Boyden, 1947, p. 666, my italics), "common position in a common plan" being either the consequence of the "ideal" form, of Naturphilosophie and NeoPlatonism, or the "logical" consequence of Geoffroy Saint-Hilaire's principle of topological invariance (Brady, 1983, p. 59; 1985, p. 117; 1994, p. 10f). Even Rieppel has enjoined this kind of theory in his explanation of hierarchical patterns of morphology (see also Patterson, 1982b,c, p. 305). For example (Rieppel, 1988, p. 146; see also Rieppel, 1989, p. 59; 1990, pp. 295, 306-307; 1992, pp. 702-703), he considered the older theory that underlies the kind of membership that these sets represent to be one of archetype or structural (idealistic) baupläne or "an a-historical or an idealistic sense, due to timeindependent laws of nature," which he then went on to point out has been "replaced by the empirical concept of generative mechanisms of form (Shubin and Alberch, 1986)." Thus, at least according to Rieppel, a "modern theory" may no longer be wanting for $D_{\mathrm{p}}$. However, whether there are any decisive empirical tests, and resulting explanations, conditional on an explanans of "generative mechanisms of form" remains to be seen because ad hoc hypotheses are effective at denying any explanation, such as the "ontogenetic re-patterning" of Wake and Roth (1989) and the genetic basis for "dissociation between traits over evolutionary time" (Mindell and Meyer, 2001). Indeed, RK made liberal use of

\footnotetext{
${ }^{9}$ Rieppel's (2002; see also Brower, 2000b) appeal to ostensive definition and intersubjectivity does not provide the solutions that he may have hoped for, because there is ample reason to believe that scientists are generally skeptical of their colleagues' research. In that light, intersubjectivity is just another word for externalism in science.
} 
just these kinds of ad hoc hypotheses in their discussions of the failure of projectability - the absence of a one-toone relational property of topological similarity among organisms (pp. 73-75). In doing so, it is plain to see that there is nothing comparable to the unambiguous scientific tests of similarity in physics and chemistry, as afforded by those sciences' special theory of atomic number (e.g., Rieppel, 1994, p. 84-87).

Further, as also noted above, RK allowed the simultaneous test of character congruence to become the basis for hypothesizing a historical explanation of those putative homologues that have survived their test(s) of similarity. However, there is a significant problem with this schedule for testing. Basically, a category mistake is made when the abstraction of a similar group of organisms is ultimately reified, as a part of history. Specifically, in making the connection between their kind of character analysis and character congruence, RK did not consider how a not-a condition is to be ultimately explained as similarity due to common ancestry. Note, what is not-a cannot be a part of any transformation (change) explanation, because not-a is nominal-it is not a thing (it is the abstract everything that $\mathbf{a}$ is not). As Hull (1964, 1978) and many others (e.g., Kluge and Farris, 1999) made perfectly clear, evolution is about things evolving from other things, species and character states. It is not about some thing in relation to no thing. The problem of reification does not seem to have been lost on Brady (1983, p. 52, italics in the original), who explained "since what follows from a given by formal identity (logical necessity) must be already contained within that given, any and all biological implications must be derived from the [given] parameters..." In other words, the outcome of a logical, set-theoretic, atemporal analysis cannot be inferred subsequently as transformation, as a causal relation involving evolutionary change (Brady, 1994; Kluge and Farris, 1999). There is no basis in set theory for either predicting or explaining what can evolve or has evolved.

Also, in limiting themselves to observation and description, without reference to any special theory, RK tacitly denied the use of those gene sequences where comparison requires insertion and deletion events (indels), because those events are only imagined, according to such a theory. RK, and pattern cladists more generally, cannot have it both ways in theory or in practice, acausally and causally.

RK were bedeviled (p. 78) by the possibility that "the search for potential homologies pursued in the light of the preferred theory of relationships may likely provide confirming primary conjectures of homology and these may also be found to be congruent." A character concept based on evolutionary transformation, an historical identity explanation of homology (the same thing perceptually), and hypothetico-deduction cover all of the concerns raised by RK, to these I now turn. The absence of requirements for similarity in what follows is no accident. They are unnecessary. To require similarity in the definitions of character and homology only renders the inference of species relationships scientifically untestable and incoherent (see below).

\section{Historical identity}

Assuming Darwin's principles of "descent, with modification," Hennig (1966, Fig. 21) clarified the relationship between transformation series and species diversification, where transformation is any heritable modification that distinguishes species from one another. Such evolutionary change, each being a necessarily unique spatio-temporally restricted event, constitutes evidence in the logic of discovering phylogenetic relationships (Kluge, 2003) and for which there is no concern for overreduction (Frost and Kluge, 1994). Evidence is then temporal and historical, not because of ontogeny or tokogeny, but because the concept species, of which the evidence is a part, imposes it. Metaphysically speaking, there is a lineage system of change, i.e., one of evolution (Lidén, 1990; Kluge, 2004).

It has long been argued that character and homology do not require measures of similarity and may nonetheless be testable (Bock, 1963, 1969a,b, 1973, pp. 386-387; see also Hennig, 1966; Wiley, 1975, p. 235; Farris, 1983; Ghiselin, 1984, 1997, pp. 204-215, 306; Eldredge, 1985; Reeck et al., 1987; contra Patterson, 1982a, p. 34; 1982b, p. 305; 1988). Consider that the concept of phylogenetic character can be defined as the observable effect of a spatio-temporally restricted event, the transformation series of Hennig. It is the observed phenotypic trait of organisms that is the hypothesized effect of this kind of causal determinism and that constitutes the basis for an empirical test of phylogenetic relationships.

Formulating an operational definition of phylogenetic character is straightforward, provided that two conditions are met. Any operation must be evolutionary - where datum and data are defined in just those terms, $d_{\mathrm{e}}$ and $D_{\mathrm{e}}$. According to Hennig (1966), and as discussed above, $d_{\mathrm{p}}$ and $D_{\mathrm{p}}$ are not equivalent to, nor are they suitable proxies for, $d_{\mathrm{e}}$ and $D_{\mathrm{e}}$. The second condition is that $d_{\mathrm{e}}$ and $D_{\mathrm{e}}$ must be testable, independent of the hypotheses of species history that they are used to test.

The phenotypic traits (characteristics, states) of species that can be hypothesized to be the same thing constitute the basis for operationalizing the phylogenetic character. In the familiar terminology of Hennig, apomorphy is the observable effect of a hypothesized transformation, that which is derived, and the same apomorph in two or more species, a synapomorphy, is perceived to be an historical identity-perceived in the 
sense of Ryle's (1949) cognitive theory, where the mind refers its sensations to a thing that is its cause. In the context of the historical relationships among species, that cause is common ancestry. This theory is not to be confused with "systematic tact" (e.g., Lorenz, 1941, pp. 198-199), the unconscious consideration of much larger numbers of characters, nor the details of similarity of any particular character. Not only is the perceptual theory of Ryle unaffected by the absence of the pure observation reports required of observational theory (as revealed, for example, by incongruent characters, regardless of a priori tests), but also, as I will now argue, that theory is readily adapted to a hypothetico-deductive kind of epistemology (see also Popper, 1963, pp. 201-214).

As noted earlier, things of any nature are self-defining. Thus, $d_{\mathrm{e}}$ and $D_{\mathrm{e}}$ are not matters of intensional definition, as RK defined $d_{\mathrm{p}}$ and $D_{\mathrm{p}}$ with regard to the relational property of topological similarity. Effectively, there is no necessary and sufficient operation for defining synapomorphy. Any operation that leads to an independently testable hypothesis of synapomorphy is acceptable. While intensional definition is absolutely denied, ostension may be employed in these hypotheses, because it is logically consistent with what is to be determined, i.e., the historical identification of things (Frost and Kluge, 1994; Kluge, 2002; see also below).

Obviously unacceptable as $d_{\mathrm{e}}$ are observations made on organisms that do not match the individuality of the taxon and character history, such as polymorphisms (Grant and Kluge, 2003; see however, e.g., Wiens, 1999). Automatically excluded are the abstract, such as covariances of biological form, i.e., morphometric "observations" (Bookstein, 1994; see, however, e.g., Cardini, 2003).

While the a priori testability of "thing hypotheses" has received little attention, it clearly constitutes that part of phylogenetic inference known as character analysis/reanalysis. There appear to be at least two kinds of acceptable tests relevant to character analysis-conjunction (Patterson, 1982a, 1988) and character compatibility (Wilson, 1965). Unacceptable is any "test of similarity" (sensu RK, see also Patterson, 1982a, 1988), because similarity can provide only a basis for intensionally defining abstract (class) concepts (pace Mahner and Bunge, 1997).

My (Kluge, 1998, p. 351) earlier objections to character compatibility in character analysis were directed to its "strong" analytical uses, such as a basis for a priori weighting, including the elimination of incompatible characters altogether, where only cliques of perfectly compatible characters are employed in delimiting species relationships. The test of character compatibility that is suggested here at the level of character analysis is as a heuristic-where incompatible characters are identified only for further research, where synapomorphies cannot be explained as unique and unreversed on the same hypothesis of species relationships, and where, having failed a test of character compatibility or conjunction, some form of systematic error is indicated. How the investigator more precisely identifies and resolves that error will depend on the circumstances that are peculiar to the characters being compared. Obviously, erroneous observation and character miscoding must be removed. At the very least, those incongruences that cannot be so resolved at the time should be highlighted in publication, thereby drawing future researchers' attention to the character hypotheses that are in need of immediate evaluation. Arguably, as the result of such a priori studies, evidence will then become more severely tested for its individuality, and the more the evidence can then be said to severely test phylogenetic hypotheses. This scientific maturity is not possible with the kind of research program that RK proposed.

The all too frequent departures from terminal addition, and the same structures developing from different embryological rudiments have rendered the empirical test of ontogeny impotent in any particular application. RK's (pp. 68-69) suggestion for saving this test, by considering hierarchies of more or less general character relations (see Nelson, 1994, p. 137), disregards the important parameter of biological time provided by ontogeny and therefore amounts to nothing more than suggesting additional tests of character congruence.

Despite Hennig's (1966) arguments to the contrary and the criticisms set forth in this paper, some may continue to "condition" their character hypotheses according to the perceived similarity of organisms' properties (Sober, 1988, pp. 130-131). Indeed, as Popper (1959, p. 32) pointed out, the basis for formulating a hypothesis matters little provided that statement is testable. The "little," however, that does matter in phylogenetic inference is that similarity should not be interpreted with regard to Geoffroy Saint-Hilaire's principle of invariance (Brady, 1994), because such a position is antagonistic, not neutral, to the theory of evolution, where variation and change are fundamental. Ostension may be employed in formulating these similarity hypotheses of species characteristics, because that kind of definition is logically consistent with the nature of what is to be determined, i.e., the spatio-temporal restrictedness of the character state. On the other hand, intensional definition, such as that employed in observational theory, cannot be used, because it leads to abstract (class) concepts, which are timeless and invariant and which may not be testable. Moreover, the use of intensional definition reopens the door to idealism and typology, including the explanation of essentialism, even if it is with regard to one of its modern generative mechanisms of form (see above). 
As for an explanation of the historical origin of form, ${ }^{10}$ a characteristic of one species is homologous to a characteristic of another species if the two characteristics can be traced phylogenetically to the same thing in the immediate common ancestor of the two species (e.g., Bock, 1963, p. 268). This is the ordinary adjectival and pronominal designation of identity, as in being 'historically the same thing' (see Oxford English dictionary). Equating 'being the same' and 'being similar' is a common mistake in the phylogenetics literature. For example, relevant to the present discussion, Brady (1983, p. 50, 56) equated the two terms (e.g., "plan" was referred to as "the same thing") and thereby claimed to be able to test an acausal classification with intensionally defined, abstract, inclusive/ exclusive similarity relations. RK (p. 65, and elsewhere) equated the relational property of topological similarity to "sameness of position," but then they intended no historical connotation at the level of character analysis. Character states are homologous if and only if they are transformation stages of the state present in the ancestor of the taxa that exhibit the homology or, expressed more succinctly, homologues are those traits that were present in the common ancestor in which they are homologous. The concept of homology is important to evolutionary theory, and codifying generalizations about what kinds of properties can be explained deductively as homologues is expected to lead to a better understanding of species relationships, and property identity. As Sober (1981, p. 170) remarked, what is important is that property sameness and difference be "rendered epistemologically accessible."

The potential for homology to be defined in a circular manner has been repeatedly underscored (e.g., Jardine, 1967, p. 125; Rieppel, 1980b, p. 315; 1991, p. 93-94; 1992, p. 712; 1994, pp. 68, 90-92; Brady, 1983, 1985, 1994; see, however, Bonde, 1977, p. 753). Clearly, there is no circularity when "homologous features are those which characterize monophyletic groups" and where "homologies are taxonomic characters" and "homology is the relation that systematists and comparative anatomists use in generating hypotheses of relationships" (Patterson, 1982a, pp. 28-29), but then there is no explanation in that purely operational definition to which circularity could be attributed. More to the point, the definition provided in the previous paragraph is not circular, because the cause of common ancestry is not explained with regard to homology. Just the opposite is the case-the phenomenon of homology is explained in terms of its cause, i.e., common ancestry. This is a typical example of the when/where explanandum of a

\footnotetext{
${ }^{10}$ An explanation of the ontogenetic origin of form is coextensive with the explanation of homology, because both are constrained by the same lineage system (e.g., Maglia et al., 2001), to which the same epistemology applies.
}

deductive historical scheme of explanation, and it is without epistemological dependence, i.e., vicious circularity (contra Brady, 1994, p. 11, 13). That the tests involved in phylogenetic systematics are reciprocally illuminating, and not circular, is evident from the fact that, even though all homologues are synapomorphies, not all synapomorphies are homologues (Hull, 1967, p. 177; Kluge, 2002, p. 590; contra Brady, 1994, p. 25).

As Hennig (1966) went to great lengths to explain, similarity cannot be the centerpiece of phylogenetic inference (contra Rieppel, 1980b). ${ }^{11}$ For example, he observed that there is no requirement that a concept of homology be "resemblance [= similarity] due to inheritance from [sic] a common ancestry" (Rieppel, 1980b, p. 315, see also Rieppel, 1980a, p. 82; 1991, pp. 97, 99; 1992, pp. 704, 708, 710; 1994, pp. 65-66, 93; 2002. p. 195; but not Rieppel, 1994, p. 66). Further, as Hennig (1966, pp. 93-94, my italics) underscored:

\begin{abstract}
Apparently it is often forgotten that the impossibility of determining directly the essential criterion of homologous characters - their phylogenetic derivation from one and the same previous condition - is meaningless for defining the concept "homology." Boyden (1947) says: "Today the pendulum has swung so far from the original implication in homology that some recommend that we define homology as any similarity due to common ancestry, as though we could know the ancestry independently of the analysis of similarities!" As though it mattered for the definition of the concept "truth" that we cannot recognize truth itself, and everywhere in science are limited to erecting hypotheses concerning truth.
\end{abstract}

The maturity that we have come to expect from the science of phylogenetic systematics increases in relation to the cycle of testability that identifies and eliminates instances of homoplasy on the most-parsimonious, total evidence hypothesis of relative recency of common ancestry, i.e., errors in the investigator's observations and codification of characters and character states (Farris, 1983; Kluge, 1998; see, however, Rieppel, 1989, pp. 55, 59-60). Discovering and correcting such mistakes is ampliative, because that knowledge feeds into the next round of research in which that evidence is used, and it is in this way that characters become increasingly more severely tested as evidence of phylogenetic relationships (Kluge, 1998, 2001, 2002, 2003). I have interpreted this process as an example of what Hennig (1966) described as reciprocal clarification (illumination), where independent tests are conducted at each turn of the cycle (Kluge, 1998; see, however, Mindell, 1991, p. 899). It is

\footnotetext{
${ }^{11}$ Hennig listed only three pages under the heading of similarity in the subject index to his 1966 book: 73, 74, and 147. However, his discussion of similarity was much more extensive than that, as indicated by the following additional pages on which he explicitly discussed similarity: 10-15, 21-23, 54-56, 76, 84-88, 92-94, 101-105, $107-108,115,117-119,122-123,125,128,133-134,140,146,148,155$, 193, 200, 202, 207, 219, 227, and 235. Indeed, his criticisms of similarity might be considered the focus of this classic work.
} 
only in this sense that, whatever role it may have played in character analysis, similarity will come to be replaced with a concept of historical identity, where it is the sophisticated falsification and the ostensive definition of things, not similarity, that count (contra Quine, 1969). One should expect not only that a proper name will be attributed to each of the most severely tested historical hypotheses of species relationships in this mature science of phylogenetics, but that an entire character terminology will move from adjectival to nounal (pace RK, pp. 63-65).

I completely agree with RK that the significance of falsification cannot be overstated when it comes to increasing objective knowledge. However, RK claimed that an a priori test(s) of similarity exists, without an accompanying underlying theory, whereas I argue that "test" in phylogenetic inference follows from assuming no less than "descent, with modification," as background knowledge. Obviously, in making such a reference, phylogenetic inference has not been purified of evolutionary theory, as pattern cladists and pheneticists have wanted. Indeed, the inference of species history is conditional on the lawfulness of those evolutionary assumptions, since they determine the testability of species relationships and the explanations of the origin of form that follow (Kluge, 2003). Observation and description alone are not sufficient to increase the testability of the evidence used in phylogenetic inference, nor can they serve as the basis for increasing objective knowledge (see epigraph).

RK sought a mechanical procedure for identifying "the" observation statement that would severely test a hypothesis of phylogenetic relationships. This is not the falsificationism of Popper's (1994) World 3, which is concerned with objective knowledge. Rather, it is the verificationism of logical positivism, of Popper's World 2 , where the concern is for the justification of true belief. Falsifiability is a normative proposal about what we should and should not regard as scientific in the phylogenetic system. The uncertainty with which RK were concerned is not even an epistemological issue in falsificationism (Kluge, 2002).

I conclude that RK failed in their quest to discover "the" method (such as the falsifiability of the relational property of topological similarity) that would provide more severely tested evidence for phylogenetic inference. Phylogenetic systematics on the other hand offers testability at all levels of analysis, the a priori character analysis, where character congruence is used to identify the most-parsimonious, least disconfirmed proposition of relative recency of common ancestry, and the a posteriori level of analysis where propositions of homoplasy are further examined for error of observation and coding. Not only have the "classical criteria of homology in the test of morphological character hypotheses" (RK, p. 59) been successfully rejected as necessary to phylo- genetic inference, but RK's demand for a "relevant technique" (pp. 62-63, 79) has been satisfied with the historical identity interpretation of characters, character analysis, and homology outlined above, at least by the "technique" that Popper (1959, p. 99) had in mind. As even Patterson (1982a, p. 36) had to concede, "the transformational [temporal] approach to homology may be more informative, and a lot more interesting than the taxic [atemporal] approach" that RK employed.

\section{Acknowledgments}

This paper was written and revised at the Cladistics Institute, Harbor Springs, Michigan. It was lengthy discussions with Olivier Rieppel and Diana Lipscomb at the Sixth International Congress of Systematic and Evolutionary Biology, September 9-16, 2002, Patras, Greece that convinced me to review the literature and summarize my long-held opinions on similarity in phylogenetic inference, including its repugnance. I am especially grateful to an anonymous reviewer for pointing out the incompleteness of many of my arguments having to do with observational theory. I also appreciate Maureen Kearney's and John Wenzel's attempts to set me straight; however, I must continue to disagree with their claims that phylogenetic inference depends necessarily on observing and codifying similarity. My debt to Willi Hennig is obvious when it comes to the concepts of evidence, character, and homology. In retrospect, I am embarrassed at how little new ground has been covered in this paper. I continue to be amazed by the number of historical biologists who seem to have overlooked significant parts of Hennig's 1966 classic, such as conceptualizing his phylogenetic systematic methodology with assumptions of evolution (transformation) and his repeated and consistent arguments against similarity. However, such oversight does not explain why pattern cladists continue to see "fit to separate and discard the metaphysical Hennigian husk of common ancestry" from how characters are perceived (Brower, 2000b, p. 13). It cannot be vicious circularity, because there is not any (contra Rieppel, 1980b, 1991, 1992, 1994; Brady, 1983, 1985, 1994).

\section{References}

Beatty, J., 1982. Classes and cladists. Syst. Zool. 31, 25-34.

Bock, W.J., 1963. Evolution and phylogeny in morphologically uniform groups. Am. Nat. 97, 265-285.

Bock, W.J., 1969a. Comparative morphology in systematics. Syst. Biol. Proc. Int. Conf. Natl. Acad. Sci. 1962, 411-448.

Bock, W.J., 1969b. The concept of homology. Ann. N. Y. Acad. Sci. 167, 71-73.

Bock, W.J., 1973. Philosophical foundations of classical evolutionary classification. Syst. Zool. 22, 375-392. 
Bock, W.J., 1977. Foundations and methods of evolutionary classifications. In: Hecht, M.H., Goody, P.C., Hecht, B.M. (Eds.), Major Patterns in Vertebrate Evolution. Plenum Press, New York, pp. 851-895.

Bock, W.J., 1989. The homology concept: its philosophical foundation and practical methodology. Bonner zool. Beitr. (NF) 32, 327-353.

Bonde, N., 1977. Cladistic classification as applied to vertebrates. In: Hecht, M.K., Goody, P.C., Hecht, B.M. (Eds.), Major Patterns in Vertebrate Evolution. Plenum Press, New York, pp. 741-804.

Bookstein, F.L., 1994. Can biometrical shape be a homologous character? In: Hall, B.K. (Ed.), Homology: The Hierarchical Basis of Comparative Biology. Academic Press, London, pp. 197-227.

Boyden, A., 1947. Homology and analogy: a critical review of the meanings and implications of these concepts in biology. Am. Midl. Nat. 37, 648-669.

Brady, R.H., 1983. Parsimony, hierarchy, and biological implications. In: Platnick, N.I., Funk, V.A. (Eds.), Advances in Cladistics 2. Columbia University Press, New York, pp. 49-60.

Brady, R.H., 1985. On the independence of systematics. Cladistics 1, 113-126.

Brady, R.H., 1994. Pattern description, process explanation, and the history of morphological sciences. In: Grande, L., Rieppel, O. (Eds.), Interpreting the Hierarchy of Nature: From Systematic Patterns to Evolutionary Process Theories. Academic Press, New York, pp. 7-31.

Brower, A.V.Z., 2000a. Evolution is not a necessary assumption of cladistics. Cladistics 16, 143-154.

Brower, A.V.Z., 2000b. Homology and the inference of systematic relationships: some historical and philosophical perspectives. In: Scotland, R., Pennington, R.T. (Eds.), Homology and Systematics: Coding Characters for Phylogenetic Analysis. Taylor \& Francis, London, pp. 10-21.

Brower, A.V.Z., 2002. Cladistics, phylogeny, evidence, and explanation-a reply to Lee. Zool. Scripta 31, 221-223.

Cardini, A., 2003. The geometry of the marmot (Rodentia: Sciuridae) mandible: phylogeny and patterns of morphological evolution. Syst. Biol. 52, 186-205.

Carine, M.A., Scotland, R.W., 1999. Taxic and transformational homology: different ways of seeing. Cladistics 15, 121-129.

Cracraft, J., 1979. Phylogenetic analysis, evolutionary models, and paleontology. In: Cracraft, J., Eldredge, N. (Eds.), Phylogenetic Analysis and Paleontology. Columbia University Press, New York, pp. 7-39.

de Pinna, M.C.C., 1991. Concepts and tests of homology in the cladistic paradigm. Cladistics 7, 367-394.

de Queiroz, K., Poe, S., 2003. Failed refutations: further comments on parsimony and likelihood methods and their relationship to Popper's degree of corroboration. Syst. Biol. 52, 352-367.

Eldredge, N., 1985. Unfinished Synthesis: Biological Hierarchies and Modern Evolutionary Thought. Oxford University Press, New York.

Farris, J.S., 1977. On the phenetic approach to vertebrate classification. In: Hecht, M.K., Goody, P.C., Hecht, B.M. (Eds.), Major Patterns in Vertebrate Evolution. Plenum Press, New York, pp. 823-850.

Farris, J.S., 1983. The logical basis of phylogenetic analysis. In: Platnick, N.I., Funk, V.A. (Eds.), Advances in Cladistics 2. Columbia University Press, New York, pp. 7-36.

Farris, J.S., Kluge, A.G., Carpenter, J.M., 2001. Popper and likelihood versus "Popper*". Syst. Biol. 50, 438-444.

Frost, D.R., Kluge, A.G., 1994. A consideration of epistemology in systematic biology, with special reference to species. Cladistics 10 , 259-294.

Geoffroy Saint-Hilaire, E., 1818. Philosophie anatomique. J.B. Bailliére, Paris.

Ghiselin, M.T., 1966. On psychologism in the logic of taxonomic controversies. Syst. Zool. 15, 207-215.
Ghiselin, M.T., 1984. "Definition," "character," and other equivocal terms. Syst. Zool. 33, 104-110.

Ghiselin, M.T., 1997. Metaphysics and the Origin of Species. State University of New York Press, Albany, New York.

Goodman, N., 1965. Fact, Fiction, and Forecast, second ed. BobbsMerrill, New York.

Goodman, N., 1970. Seven strictures on similarity. In: Foster, L., Swanson, J.W. (Eds.), Experience and Theory. Duckworth, London, pp. 19-29.

Grande, L., Rieppel, O., 1994. Interpreting the hierarchy of nature: from systematic patterns to evolutionary process theories. Academic Press, San Diego, CA.

Grant, T., 2002. Testing methods: the evaluation of discovery operations in evolutionary biology. Cladistics 18, 94-111.

Grant, T., Kluge, A., 2003. Data exploration in phylogenetic inference: scientific, heuristic, or neither. Cladistics 19 (in press).

Hauser, D.L., Presch, W., 1991. The effect of ordered characters on phylogenetic reconstruction. Cladistics 7, 243-265.

Hennig, W., 1966. Phylogenetic Systematics. University Illinois Press, Urbana, IL.

Hull, D.L., 1964. The effect of essentialism on taxonomy: two thousand years of stasis (I). Br. J. Philos. 15, 314-326.

Hull, D.L., 1967. Certainty and circularity in evolutionary taxonomy. Evolution 21, 174-189.

Hull, D.L., 1978. A matter of individuality. Philso. Sci. 45, 335-360.

Jardine, N., 1967. The concept of homology in biology. Br. J. Philos. $18,125-139$

Jardine, N., 1969. The observational and theoretical components of homology: a study based on the morphology of the dermal skull roofs of rhipidistian fishes. Biol. J. Linn. Soc. 1, 327-367.

Källersjö, M., Albert, V.A., Farris, J.S., 1999. Homoplasy increases phylogenetic structure. Cladistics 15, 91-93.

Kitching, I.J., Forey, P.L., Humphries, C.J., Williams, D.M., 1998. Cladistics: the theory and practice of parsimony analysis. Syst. Assoc. Publ. 11 (second ed.).

Kluge, A.G., 1989. A concern for evidence and a phylogenetic hypothesis of relationships among Epicrates (Boidae, Serpentes). Syst. Zool. 38, 7-25.

Kluge, A.G., 1998. Sophisticated falsification and research cycles: consequences for differential character weighting in phylogenetic systematics. Zool. Scripta 26, 349-360.

Kluge, A.G., 2001. Philosophical conjectures and their refutation. Syst. Biol. 50, 322-330.

Kluge, A.G., 2002. Distinguishing "or" from "and," and the case for historical identification. Cladistics 18, 585-593.

Kluge, A.G., 2003. On the deduction of species relationships: a précis. Cladistics 19, 233-239.

Kluge, A.G., 2004. Cladistic taxonomy in theory and practice. In: Donnelly, M.A., Crother, B.I., Guyer, C., Wake, M.H., White, M.E. (Eds.), Ecology and Evolution in the Tropics: A Herpetological Perspective. University of Chicago Press, IL (in press)

Kluge, A.G., Farris, J.S., 1999. Taxic homology: Overall similarity. Cladistics 15, 205-212.

Lipscomb, D.L., 1992. Parsimony, homology, and the analysis of multistate characters. Cladistics 8, 45-65.

Lipscomb, D.L., 1998. Basics of Cladistic Analysis. Privately printed, George Washington University, DC.

Lidén, M., 1990. Replicators, hierarchy, and the species problem. Cladistics, 6,183-186.

Lorenz, K., 1941. Vergleichende Bewegungsstudien an Anatinen. J. Ornithol. 3, 206-293.

Maglia, A.M., Pugener, L.A., Trueb, L., 2001. Comparative development of anurans: using phylogeny to understand ontogeny. Am. Zool. 41, 538-551.

Mahner, M., Bunge, M., 1997. Foundations of biophilosophy. Springer, New York. 
Maslin, T.P., 1952. Morphological criteria of phyletic relationships. Syst. Zool. 1, 49-70.

Mindell, D.P., 1991. Similarity and congruence as criteria for molecular homology. Mol. Biol. Evol. 8, 897-900.

Mindell, D.P., Meyer, A., 2001. Homology evolving. Trends Ecol. Evol. 16, 434-440.

Naef, A., 1917. Die individuelle Entwicklung organischer Formen als Urkunde ihrer Stammesgeschichte. G. Fischer Verlag, Jena.

Naef, A., 1919. Idealistische Morphologie und Phylogenetik. G. Fischer Verlag, Jena.

Nagel, E., 1979. The Structure of Science. Hackett, Indianapolis, IN.

Nelson, G., 1994. Homology and systematics. In: Hall, B.K. (Ed.), Homology: The Hierarchical Basis of Comparative Biology. Academic Press, New York, pp. 101-149.

Patterson, C., 1978. Verifiability in systematics. Syst. Zool. 27, 218222.

Patterson, C., 1982a. Morphological characters and homology. In: Joysey, K.A., Friday, A.E. (Eds.), Problems of Phylogenetic Reconstruction. Academic Press, New York, pp. 21-74.

Patterson, C., 1982b. Cladistics and classification. New Scientist 94, 303-306.

Patterson, C., 1982c. Classes and cladists or individuals and evolution. Syst. Zool. 31, 284-286.

Patterson, C., 1983. How does phylogeny differ from ontogeny. In: Goodwin, B.C., Holder, N., Wylie, C.C. (Eds.), Development and Evolution. Cambridge University Press, Cambridge, MA, pp. 1-31.

Patterson, C., 1988. Homology in classical and molecular biology. Mol. Biol. Evol. 5, 603-625.

Platnick, N.I., 1978. Classifications, historical narratives, and hypotheses. Syst. Zool. 27, 365-369.

Platnick, N.I., 1979. Philosophy and the transformation of cladistics. Syst. Zool. 28, 537-546.

Platnick, N.I., 1982. Defining characters and evolutionary groups. Syst. Zool. 31, 282-284.

Pogue, M.G., Mickevich, M.F., 1990. Character definitions and character state delineation: the bête noire of phylogenetic inference. Cladistics 6, 319-361.

Popper, K., 1957. The Poverty of Historicism. Routledge, London.

Popper, K., 1959. The Logic of Scientific Discovery. Harper and Row, New York (1968 edition).

Popper, K., 1963. Conjectures and refutations: the growth of scientific knowledge. Harper and Row, New York (1968 edition).

Popper, K., 1972. Objective Knowledge: An Evolutionary Approach. Clarendon Press, Oxford.

Popper, K., 1994. Knowledge and the Mind-body Problem: In Defence of Interaction. Routledge, New York.

Quine, W.O., 1969. Ontological relativity and other essays. Columbia University, New York.

Quine, W.O., 2000. Three networks: similarity, implication, and membership. In: Kanamori, A. (Ed.), Analytic Philosophy and Logic. Vol. VI. The Proceedings of the Twentieth World Congress of Philosophy. Philosophy Documentation Center, Bowling Green State University, Bowling Green, OH, pp. 287-291.

Reeck, G.R., de Haën, C., Teller, D.C., Doolittle, R.F., Fitch, W.M., Dickerson, R.E., Chambon, P., McLachlan, A.D., Margoliash, E., Jukes, T.H., Zuckerkandl, E., 1987. Homology in proteins and nucleic acids: a terminology muddle and a way out of it. Cell 50, 667.

Riedl, R., 1975. Die Ordnung des Lebendigen. Systembedingungen der Evolution. Paul Parey, Hamburg.
Rieppel, O., 1980a. Why to be a cladist. Z. Zool. Syst. Evol. 18, 81-90. Rieppel, O., 1980b. Homology, a deductive concept? Z. Zool. Syst. Evol. 18, 315-319.

Rieppel, O., 1988. Fundamentals of Comparative Biology. Birkhäuser, Basel.

Rieppel, O., 1989. Character incongruence: noise or data? Abhandl. Naturwiss. Vereins Hamburg (NF) 28, 53-62.

Rieppel, O., 1990. Structuralism, functionalism, and the four Aristotelian causes. J. History Biol. 23, 291-320.

Rieppel, O., 1991. Things, taxa and relationships. Cladistics 7, 93-100.

Rieppel, O., 1992. Homology and logical fallacy. J. Evol. Biol. 5, 701715.

Rieppel, O., 1994. Homology, topology, and typology: the history of modern debates. In: Hall, B.K. (Ed.), Homology: The Hierarchical Basis of Comparative Biology. Academic Press, London, pp. 63 100.

Rieppel, O., 2002. The meaning of homology. In: Biodiversity in the Information Age. [abstracts] Sixth International Congress of Systematic and Evolutionary Biology. Department of Biology, University Patras, Patras, Greece, p. 195.

Rieppel, O., Grande, L., 1994. Summary and comments on systematic pattern and evolutionary process. In: Grande, L., Rieppel, O. (Eds.), Interpreting the Hierarchy of Nature: From Systematic Patterns to Evolutionary Process Theories. Academic Press, New York, pp. 227-255.

Rieppel, O., Kearney, M., 2002. Similarity. Biol. J. Linn. Soc. 75, 5982.

Rieppel, O., Kluge, A.G., Zaher, H., 2002. Testing the phylogenetic relationships of the Pleistocene snake Wonambi naracoortensis Smith. J. Vertebr. Paleontol. 22, 812-829.

Russell, E.S., 1916. Form and Function: A Contribution to the History of Animal Morphology. Murray, London (1982 University of Chicago reprint, with an introduction by George V. Lauder).

Ryle, G., 1949. Concept of Mind. Hutchinson's Library, New York.

Shubin, N.H., Alberch, P., 1986. A morphogenetic approach to the origin and basic organization of the tetrapod limb. Evol. Biol. 20, 319-387.

Sober, E., 1981. Evolutionary theory and the ontological status of properties. Philos. Stud. 40, 147-176.

Sober, E., 1988. Reconstructing the Past: Parsimony, Evolution, and Inference. MIT Press, Cambridge, MA.

Sober, E., Lewontin, R.C., 1982. Artifact, cause, and genic selection. Philos. Sci. 49, 157-180.

Sokal, R.R., Sneath, P.H.A., 1963. Principles of numerical taxonomy. Freeman, San Francisco, CA.

Wake, D.B., Roth, G., 1989. The linkage between ontogeny and phylogeny in the evolution of complex systems. In: Wake, D.B., Roth, G. (Eds.), Complex Organismal Functions: Integration and Evolution in Vertebrates. Wiley, New York, pp. 361-377.

Whiting, M.F., Bradler, S., Maxwell, T., 2003. Loss and recovery of wings in stick insects. Nature 421, 264-267.

Wiens, J.J., 1999. Polymorphism in systematics and comparative biology. Annu. Rev. Ecol. Syst. 30, 327-362.

Wiley, E.O., 1975. Karl R. Popper, systematics, and classification: a reply to Walter Bock and other evolutionary taxonomists. Syst. Zool. 24, 233-242.

Wilson, E.O., 1965. A consistency test for phylogenies based on contemporaneous species. Syst. Zool. 14, 214-220.

Woodger, J.H., 1952. Science without properties. Br. J. Philos. Sci. 2 , 193-216. 